\title{
Improving Shoestring Surveys for Off-grid Humanitarian Power Projects: Kilowatts for Humanity and KoboCollect
}

\author{
Peter Dauenhauer, ${ }^{\mathrm{i}, \mathrm{ii}}$, Dr Matt Shields, ${ }^{\mathrm{i}}$ Dr J. McLean Sloughter ${ }^{\mathrm{i}}$, Dr AJ Stewart ${ }^{\mathrm{i}}$, Christopher Lacrampe ${ }^{\mathrm{i}}$, Elsa \\ Magness $^{\mathrm{iii}}$, Jeffrey Ochavillo ${ }^{\mathrm{i}}$, Jason Limfueco ${ }^{\mathrm{i}}$, Alyssa Mendoza ${ }^{\mathrm{i}}$ \\ ${ }^{\mathrm{i}}$ Seattle University, ${ }^{\mathrm{ii}}$ University of Strathclyde, iii Bryn Mawr College
}

\begin{abstract}
Field surveys are commonplace and essential for off-grid power projects in developing countries where availability of data may be scarce. Critical decisions such as site selection, technology choice, business models employed, and approach to community engagement are all greatly assisted by data that can be gathered through field surveys. Paper-based field surveys, the de facto standard approach, are prone to error, slow to deploy and adjust, and have other practical challenges despite the obvious advantage of having fewer technological dependencies. Over recent years, improvement in freely available surveying software, smartphones and tablets, as well as good cellular coverage throughout the world offers humanitarian organizations an opportunity to implement digital field surveys with relative ease. This article presents the experience implementing KoboCollect by Kilowatts for Humanity (KWH), a non-profit that implements sustainable energy kiosks in developing countries. KoboCollect is an open-source data collection software platform designed to support humanitarian and research organizations. In this paper, limitations of paper-based field surveys from previous KWH projects, as well as from the extant literature, are considered with respect to their ultimate impact on the implementation of the development project. A new approach is presented in which survey questions are refined based on past experience and are directly related to pre-defined project indicators. Key benefits and challenges are identified from the adoption of the new approach and methodological questions around sampling and decision-making following data collection are discussed. The new method is discussed in the context of a KWH survey project being conducted in the summer of 2018 in three locations in the Philippines. A major goal of this work is to open a discussion about the successes and failures of the shoestring, paper-based survey methodology and point to current best practices.
\end{abstract}

Keywords- Energy Use Surveys, Developing Countries, Electricity Access, Digital Survey.

\section{INTRODUCTION}

\section{A. Electricity Access Situation}

According to World Bank data in 2017, approximately 1.06 billion people lack access to electricity [1]. In recent years, significant cost reduction in solar modules has made implementation of off-grid microsystems in areas lacking energy access more feasible. These microsystems can be constructed in extremely rural areas where access to the electrical grid is financially unfeasible.

Although the Philippines has electricity usage of about 87.2 percent, a large number of the surrounding islands that are part of the country are not able to gain access to the grid. According to the Philippine Statistics Authority approximately $30.3 \%$ of households used kerosene as a light source in 2011. The only option for some of these communities to have access to power is the construction of an off-grid system.

Although solar modules have decreased in price, batteries and inverters are an essential part of an off--grid solar system and are still quite expensive for energy impoverished communities. The effective life of the batteries is less than 5 years depending on usage. In order to create a sustainable project it is not enough to have an efficient system design, there must also be an informed business plan for the community to be able to effectively monetize the energy generated in order to replace the batteries and other components when necessary.

\section{$B$. How surveys are used in energy access projects}

Surveys are an integral part of the design process in Kilowatts for Humanity (KWH). The data collected by the surveys gives information about the population, economy, and energy usage of the local community. This information gets used for three general areas.

- $\quad$ NGO Vetting. The first and foremost use of survey collection is to determine the effectiveness of KWH's relationship with the local NGO. If the collection of the surveys fails completely, then 
KWH may revisit its relationship with the NGO. The surveys are the first task that the NGO is required to complete and thus is the first impression of its capacity as a partner.

- Potential Kiosk Revenue. Questions asked on the survey include items the community member purchase in town. These could include ice, cold drinks, or other items that require electricity. This information is used to develop a list of products that the kiosk can sell in order to generate revenue for the future system costs.

- System Design. The data collected from the surveys gives details about the usage of energy within the community. Whether this be for lighting, entertainment, agriculture, or refrigeration. For instance, if a large portion of the community travels kilometers for ice, then the specifications of the kiosk should include the capacity to power some number of freezers.

\section{Paper survey process with a local NGO partner}

The entire process of paper survey collection has traditionally be done by the NGO. Although KWH reviews the surveys afterwards there are no KWH employees "on the ground." First, KWH adjusts the general template of our surveys to include specific questions that are related to the community of interest. These questions are based on the initial assessment trip. Once the surveys have been adjusted, they are sent electronically to our local NGO partner.

As soon as our NGO partner receives the surveys they must print out the required number, normally around 50 or so, and recruit volunteers to visit the community in order conduct the surveys. In the village, the volunteers visit households and conduct the surveys. The surveys are normally conducted during the day and given to an adult in the household that has an income.

Depending on the location of our potential site, this could take weeks because multiple visits might be necessary in order to collect sufficient surveys. Weather and difficult roads can make travel to rural areas expensive.

Once all surveys have been collected, the NGO must scan and send the surveys back electronically. Depending on the location of the NGO office, access to a scanner might be difficult. So this is may not be an immediate action. Finally, after KWH has received the scanned copies of the survey, the data must be transcribed into Excel or other statistical software in order to perform sufficient analysis on the data.

Paper based surveys offer many challenges throughout the process of data collection. The one benefit of paper surveys is that any local survey volunteers require little to no training in order to conduct a survey.
The challenges are numerous:

- Printing surveys in-country is sometimes difficult and costly for the NGO

- Surveys must be physically handled, distributed, and returned to NGO by volunteers

- Local NGO can have difficulty scanning and emailing surveys

- The process is elongated as a result of the NGO needing to first print then scan and send surveys

- Transcribing data from surveys into statistical software is difficult and time consuming

- The handwriting of volunteers is sometimes illegible.

- The units of measurement used among volunteers is not uniform

- Volunteers may write qualitative answers in quantitative sections

In 2017 KWH implemented a project in Munyama, Zambia. The time it took to collect the data from sending the surveys to the NGO to having the data entered into an excel file was approximately 5 months. This is partially due to weather preventing the NGO from visiting the village, but also access to the internet and a scanner were also an issue. The final data collected was also difficult to process as the volunteers who conducted the surveys did not use the same system of measurement (or did not make units clear) for questions involving fishing. As Munyama was a fishing village, this made any design in the business plan with regards to fish refrigeration difficult.

\section{Pros and Cons of the Digital Surveying Process}

As opposed to a paper-based survey process the use of a digital platform has several inherent strengths which amount to the potential of higher quality data achieved in greater quantities at greater speeds. KoboCollect, a data collection app linked to KoboToolkit, an online open-source platform for survey deployment, is highlighted in this paper [2]. There are several prominent alternatives which have various features and costs [3] - [6].

The main benefits to the digital approach can be summarized as: increased features, improved survey process, and more accurate / timely data entry. However, as cautioned by Dette [7], use of technology can also introduce some challenges such as distrust, added dependencies, and increased capacity requirements for the research team. Finally, major issues in all field surveys, such as biases (surveyor, respondent, etc.) and sampling challenges are not obviated with this technology [7].

Benefits from the use of a mobile phone or tablet include the availability of a range of sensors to the surveying process. Notably this includes a GPS device, camera, microphone, and ability to dynamically compute values. Additionally, creating 
structured forms that require entry before moving on and pathing for follow up questions makes skipping sections both more controlled and smarter. Some cases of human error can be avoided for example by including data validation at the time of input and elimination of the need to digitize paper surveys.

At the same time, problems can arise including the inherent requirement to have more technological dependencies, in this case a mobile phone, which requires a power supply, has a moderate expense to purchase, and is subject to malfunction in difficult environmental conditions. Training a team to use new technology is time consuming and sometimes unintuitive. Investing too little time into training can instead result in higher frequency of error, misunderstanding, and coping behaviors such as entering random data to move on. Finally, to respondents (and enumerators) unfamiliar with the technology, there may be an initial skepticism that at best slows down the process as additional explanation is needed; at worst respondents may opt out of the survey.

\section{E. Research Need \& Paper Objectives}

Practitioners and communities often require survey data in order to make critical decisions around project designs and implementation approaches. In remote areas, data availability is low, and paper-based collection processes have been shown to be time consuming and error prone.

This article is aimed at exploring the use of KoboCollect, an open-source data collection application on mobile phones to carry out pre-feasibility surveys for off-grid electrification projects in developing countries. Firsthand experience from the Seattle, USA-based Kilowatts for Humanity NGO on a trial of the technology in the Philippines provides a new perspective on the strengths and weaknesses of the technology. While the results of the energy use in two villages in the Philippines provides some information for the design of a sustainable offgrid project, we also strive to discuss the process, lessons learned, and provide recommendations for others undertaking similar studies.

The paper is organized as follows. First, the introductory Section I covers the energy access landscape, current need for electrification, and role of surveys to inform project design. Our methodology for the implemented survey, location, sampling approach and survey plan are covered in Section II. A selection of the results are shown in Section III along with feedback gathered throughout the process. Section IV concludes the paper with implications and recommendations for NGOs undertaking similar studies.

\section{Methodology}

\section{A. Description of Survey}

The KWH survey used in this study covers several topical areas including household demographics, energy use, availability of financial products, and need for potential future services shown in Table I. It is intended that the results, together with qualitative data from focus group meetings and feedback from a local NGO partner, form the basis for selecting a site to receive an off-grid kiosk. The survey has a total of 122 potential questions, though it is unusual to ask all the questions as subsections are skipped if unnecessary. Note, the actual household survey used in the study is available upon request to the corresponding author.

TABLE I. HOUSEHOLD SURVEY SECTIONS

\begin{tabular}{|c|c|}
\hline Section and Contents & Purposes \\
\hline $\begin{array}{l}\text { Household Characteristics } \\
\text { Count of } \mathrm{M} / \mathrm{F} \text { in age } \\
\text { brackets } \\
\text { Sources of income }\end{array}$ & $\begin{array}{l}\text { Monitoring and evaluation } \\
\text { Relate income and } \\
\text { seasonality to potential } \\
\text { businesses opportunities }\end{array}$ \\
\hline $\begin{array}{l}\text { Household Energy Use and } \\
\text { Expenditures } \\
\text { Conventional sources } \\
\text { Charged batteries } \\
\text { Home generators } \\
\text { Solar Products }\end{array}$ & $\begin{array}{l}\text { Identify current level of } \\
\text { energy need, determine } \\
\text { pricing for competing } \\
\text { energy sources, estimate a } \\
\text { market size, identify } \\
\text { products which could be } \\
\text { substituted }\end{array}$ \\
\hline $\begin{array}{l}\text { Availability of Financial } \\
\text { Products } \\
\text { Level of debt } \\
\text { Nature of debt } \\
\text { Interest rates }\end{array}$ & $\begin{array}{l}\text { Make use of prevailing } \\
\text { financial products or identify } \\
\text { an opportunity to provide } \\
\text { financing }\end{array}$ \\
\hline Need for potential services & $\begin{array}{l}\text { Initially identify potential } \\
\text { businesses that could be } \\
\text { supplied by electricity that } \\
\text { are in high demand. }\end{array}$ \\
\hline
\end{tabular}

\section{B. Digital survey development and deployment}

The survey is converted to a digital environment using a spreadsheet editor and the XLSform format [9], which has good online documentation. The completed form is uploaded to the KoboToolbox servers where the sections are parsed and defined into a tabular format. The platform provides an online form editor which may be more intuitive to some users.

Once deployed, the survey can be accessed through the KoboCollect application. Generally, most smart phones with Android $6+$ can use this app. The enumerator accesses the appropriate server URL and downloads the blank survey. When making adjustments after a pilot of the survey, changes can be made remotely and the survey updated in short succession.

The study survey is facilitated by an enumerator. In this arrangement, once the survey is downloaded, no further access to internet is needed as completed surveys are stored on the device and require very little space. For most of the sites 
considered by $\mathrm{KWH}$, internet availability can be inconsistent, slow or completely unavailable. The app uploads all completed surveys once a connection is available.

\section{Sampling and Question Choice}

In administering surveys, it is important to make sure that those surveyed are representative of the community as a whole. Doing so generally requires contextual knowledge of the community being surveyed. As such, the local NGO partner plays a vital role. Survey participants should be selected to appropriately represent the economic, professional, and geographic diversity of the community.

It is also important to develop survey questions that will best capture relevant information. It is often the case that many people within a community will have professions in which their income has strong seasonal variability, and so questions about typical monthly income will not provide an adequate picture of their financial circumstances. Past projects implemented by $\mathrm{KWH}$ have also found that survey responses about how much someone would be willing to spend for new energy services can prove to be poor predictors of actual spending once services become available. These are often better predicted based on current energy spending [10] [11].

\section{Philippines surveying plan}

A case study was planned in collaboration with Stiftung Solarenergie Philippines (STS) [12] to conduct a series of initial assessments in Coron, Palawan (Philippines) in June 2018. The respondents were members of the Tagbanua tribe living in several different off-grid Sitios (small villages), and were administered the survey described in Section IIA to assess their economic status and their willingness to pay for electrified services.

Surveys were given to STS to review alongside a teleconference walkthrough of each question lasting around 2 hours in total. Immediate feedback was provided which included question and answer wording, adding particular answer options which were not present, and removing questions or options that were not relevant to the context. A short written guide for using the technology was created by KWH. STS reviewed the surveys and provided further feedback that was used to revise the survey. Paper-based surveys were developed alongside as a backup for any problems that may be experienced with the technology.

\section{RESULtS}

\section{A. Results of Data Gathered}

Three communities were surveyed: Sitio Napuagan, Sitio Bucatan, and Sitio Camanga. There were 14 respondents in Sitio Napuagan ( 9 female and 5 male), 9 in Sitio Bucatan (7F, 2M), and 8 in Sitio Camanga (5F, 3M). The communities' livelihoods were dominated by fishing where $87 \%$ of households indicated fishing as their primary source.

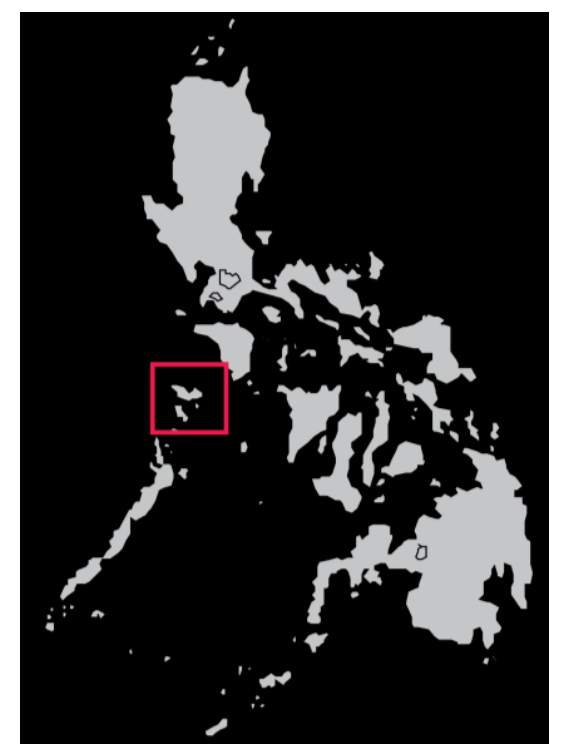

Fig. 1. Coron Region, Philippines



Fig. 2. Monthly Household Income by Village

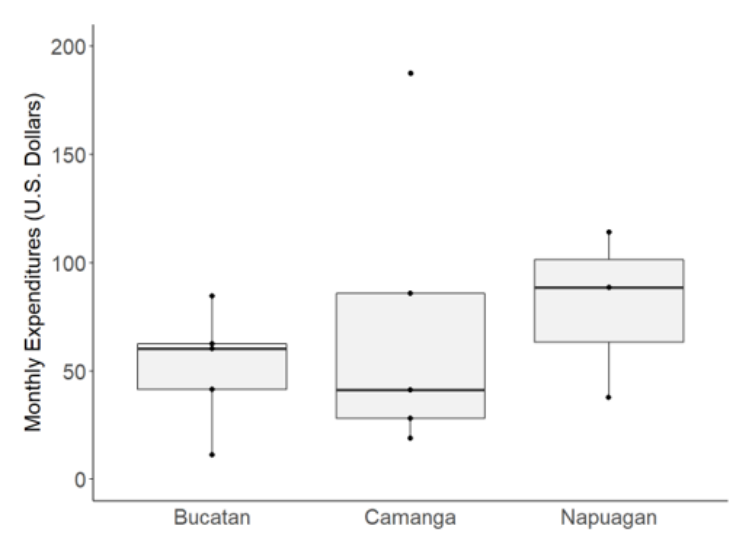

Fig. 3. Monthly Household Expenditure by Village 
Ages of respondents at all sites ranged from 19 years to 60 years, with a median age of 39 years. Household size ranged from 2 to 9 people, with a median size of 5 .

Monthly household income by village is shown in Figure 2. The median income of $16(51.6 \%)$ respondents who reported a known income was $\$ 50.49$ (Converted from P\$ to \$USD at $53.4: 1)$. Of the 10 survey respondents who indicated fishing activities, $80 \%$ (8) reported a yearly income value (two fishers reported keeping their catch for personal use). This yearly value was adjusted to an average monthly rate, and aggregated with reported nonagricultural monthly incomes to derive the total. The median monthly fishing income was $\$ 36.49$ for fishers who reported some level of income. 29\% (9) of all respondents reported a specific value for non-agricultural monthly incomes, while 51.6\% (16) acknowledged some level of non-agricultural income but were unable to quantify that value. The median monthly non-agricultural income of those who reported some value was \$37.45. Although the survey included a farming/harvesting subsection, none of the surveys recorded responses to that section.

For all three locations, reported median monthly expenditures was $\$ 61.31$, dropping non reporting respondents. Most respondents' expenses varied from $\$ 40$ - $\$ 100$ as shown in Figure 3. 90.4\% (28) of the total observations recorded some level of monthly expenditure. In total, 14 respondents, $45.16 \%$ of all respondents, reported both their monthly income and expenditures, with $57.17 \%$ (8) of these having higher reported expenditures than income. In one case, one respondent reported spending \$781.29 more than they earned, while the lowest loss (and the median after expenditure income) reported was $\$ 15.52$. In Sitio Napuagan, 3 respondents reported their income and expenditures, and in all cases their profits were negative. In Sitio Bucatan, 6 respondents reported their income and expenditures, and 2 of these had negative profit. Lastly, in Sitio Camanga, 3 out of the 5 surveyed reported negative profit.

When turning to an analysis of each village (Figures 2 and 3 ), we find the highest monthly incomes for Sitio Bucatan of $\$ 103.00$ and monthly expenditures of $\$ 61.42$ (6 observations). For Sitio Camanga we find median monthly incomes of $\$ 82.58$ and median expenditures of $\$ 41.18$ (5 observations). For Sitio Napuagan we find median monthly incomes of $\$ 37.45$ and median monthly expenditures of $\$ 88.54$ (3 observations).

Existence of financial products was extremely limited, only 2 of 31 households indicated that they had any type of household debt and a formal bank account. Although most households were interested in the potential new businesses (only 10 - $15 \%$ answered), battery charging, cold drinks, agricultural refrigeration, mobile phone charging, and a powered community room were fairly equally valued among those who did answer. $13 \%$ respondents also indicated that a water system would be desired.

\section{B. Feedback on Process}

A retrospective assessment of the survey process with STS enumerators identified several critical issues with the use of the KoboCollect surveys which are categorized as either technology difficulties or cultural context.

In the former category, STS volunteers reported that they only received the mobile phones used to administer the surveys a few days before the assessment trip; as a result, the enumerators were unfamiliar with the devices and were uncomfortable reading questions and entering answers in a timely manner. Furthermore, STS did not account for the amount that the phone batteries would discharge during the daylong trip to the Sitios. By the time the surveys had begun, most of the phone batteries were nearly dead and the enumerators decided it was not worthwhile to risk losing data if the phones shut off. In the retrospective assessment, STS and KWH agreed that these are temporary obstacles that can be easily overcome with more exposure to the technology and better trip preparation.

The second category of issues with digital surveying, cultural context, is more significant. While many of the STS enumerators were unable to attempt to use the phones to collect data, several surveys were begun with phones that still had sufficient battery life. The enumerators found that the respondents were not familiar with smartphone technology, and as a result were distracted by the phones themselves. This resulted in delays and confusion while answering questions until the enumerators decided to put the phones away and revert to paper surveys. In addition, eye-to-eye contact was broken with the respondents while data was being entered in the phone; this is an unusual cultural behavior for the tribes living in the Coron region and caused the respondents to become uncomfortable. This discomfort was not reported for the cases in which paper surveys were used.

The issues with cultural context are less easily addressed than the technology difficulties, which simply required more preparation time. If a respondent is inherently uncomfortable with the technology or use of technology associated with collecting the online KoboCollect data, it is not reasonable to expect this person to change their perspective during the course of the interview. This will naturally impact the accuracy and quality of their responses. This is additionally complicated as it is difficult for an outside organization such as KWH to predict which respondents will or will not be comfortable in the presence of smart phones. Furthermore, any experience gained in the impact of technology on respondents' ability to provide meaningful survey responses may not scale between different communities. For instance, previous KWH projects in rural Zambia have demonstrated that younger community members (16-25 years old) are capable of using devices such as tablets without prior experience and were interested and energized by the presence of technology. This experience did not translate to the assessment trip in the Philippines. 


\section{CONCLUSIONS}

In May 2018 KWH and STS implemented an energy use survey in three villages in the Coron region. KWH's previous paper based survey was converted to a digital format and deployed via the KoboToolbox platform.

While the actual data collected in these surveys was important and is useful for site selection, as discussed in Section IIIA, it is discouraging that the impact of KoboCollect could not be assessed during this case study in the Philippines. However, this represents a significant data point in the design of future assessment trips. A key finding is that it is clear that the implementation of the KoboCollect survey is challenging for both the enumerators and the respondents. It is important to recognize that assumptions when trying to implement technology may not be correct, for example the level of conspicuousness of the technology and the enumerator familiarity with the digital surveying process. Sufficient preparation and training is required to ensure that both sides of the interview are comfortable with its use. Additionally, the use of a pilot would help to identify new constraints earlier on so these can be overcome before full implementation.

Additional communication with the survey administrators about cultural context will need to be incorporated into the collaboration process. STS is conducting further surveys in the Coron region in the coming months and will again try to implement the KoboCollect methodology.

\section{V.ACKNOWLEDGEMENT}

The authors would like to thank STS Philippines and

Kilowatts for Humanity dedicated volunteers for their support.

\section{REFERENCES}

[1] World Bank. State of Electricity Access Report. Washington DC. 2017.

[2] KoboToolbox, http://www.kobotoolbox.org

[3] FieldData, http://fieldata.org/

[4] NOMAD, https://humanitarian-nomad.org/

[5] Open Data Kit, https://opendatakit.org/

[6] magpi, https://home.magpi.com/

[7] Dette, R. 2016. Do No Digital Harm: Mitigating Technology Risks in Humanitarian Contexts. EPFL-UNESCO Conference on Technologies for Development. Lausanne, Switzerland. 2016.

[8] Blodgett, C., Dauenhauer, P., Louie, H. and Kickham, L., 2017. Accuracy of energy-use surveys in predicting rural mini-grid user consumption. Energy for Sustainable Development, 41, pp.88-105.

[9] XLSForm.org, http://xlsform.org/

[10] Van Acker V., Szablya S. J., Louie H., Sloughter J.M., and Pirbhai A. S., Survey of energy use and costs in rural kenya for community microgrid business model development. IEEE Global Humanitarian Technology Conference (GHTC 2014). San Jose, CA. 2014. pp. 166173.

[11] Sloughter J.M., Isakson J., Mak Y.P., Schliecher K., Louie H., Shields and K., Salmon M., Designing a sustainable business plan for an offgrid energy kiosk in Chalokwa, Zambia. IEEE Global Humanitarian Technology Conference (GHTC 2016). Seattle, WA. 2016. pp. 401-405.

[12] Stiftung Solarenergie (STS), https://stiftung-solarenergie.de/ 